\title{
Left ventricular performance early after repair for posterior mitral leaflet prolapse: Chordal replacement versus leaflet resection
}

\author{
Ken-ichi Imasaka, MD, PhD, Eiki Tayama, MD, PhD, and Yukihiro Tomita, MD, PhD
}

\section{ABSTRACT}

Objective: To review hemodynamic performance early after valve repair with chordal replacement versus leaflet resection for posterior mitral leaflet prolapse.

Methods: Between April 2006 and September 2014, 72 consecutive patients underwent valve repair with chordal replacement (30 patients) or leaflet resection (42 patients) for isolated posterior mitral leaflet prolapse. Left ventricular ejection fraction, end-systolic elastance, effective arterial elastance, and ventricular efficiency were noninvasively measured by echocardiography and analyzed preoperatively and $\sim 1$ month postoperatively. Mitral valve repair was accomplished in all patients, and no regurgitation (including trivial) was observed postoperatively.

Results: Chordal replacement resulted in significantly less reduction in left ventricular ejection fraction, and significantly greater increase in end-systolic elastance than leaflet resection (left ventricular ejection fraction, $4.8 \%$ vs $16.7 \%$ relative decrease $[P=.005]$ and end-systolic elastance, $19.0 \%$ vs $-1.3 \%$ relative increase $[P=.012])$. Despite comparable preoperative ventricular efficiency between the groups, the postoperative ventricular efficiency in the chordal replacement group was superior to that in the leaflet resection group (ventriculoarterial coupling, $32.0 \%$ vs $89.3 \%$ relative increase $[P=.007]$ and ratio of stroke work to pressure-volume area, $4.3 \%$ vs $13.4 \%$ relative decrease $[P=.008])$. In multivariate analysis, operative technique was a significant determinant of left ventricular ejection fraction and ratio of stroke work to pressure-volume area $(P=.030$ and $P=.030$, respectively).

Conclusions: Chordal replacement might provide patients undergoing valve repair for posterior mitral leaflet prolapse with better postoperative ventricular performance than leaflet resection. Longer follow-up is required to compare long-term outcomes. (J Thorac Cardiovasc Surg 2015;150:538-45)

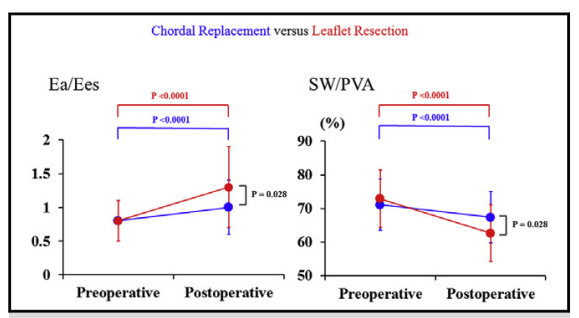

Changes in left ventricle efficiency between chordal replacement and leaflet resection.

\section{Central Message}

Our findings suggest that left ventricle performance in patients undergoing chordal replacement is superior to that in leaflet resection.

\section{Perspective}

Little is known regarding the relative superiority of chordal replacement or leaflet resection as operative techniques for valve repair in posterior mitral leaflet prolapse. Our findings suggest that left ventricle performance after chordal replacement is superior to that after leaflet resection. This result contributes to clarifying the optimal technique to preserve left ventricle function in patients undergoing mitral valve repair for posterior mitral leaflet prolapse.

See Editorial Commentary page 546.

See Editorial page 448.
Mitral valve (MV) repair is now the standard treatment for the majority of patients with degenerative mitral regurgitation (MR). In general, prolapse of the posterior mitral leaflet (PML) is more common than prolapse of

\footnotetext{
From the Department of Cardiovascular Surgery, Clinical Research Institute, National Hospital, Organization Kyushu Medical Center, Fukuoka, Japan.

Statistical analyses were conducted in consultation with Professor Masahiro Nakano, $\mathrm{PhD}$, Junshin Gakuen University.

Received for publication March 3, 2015; revisions received May 19, 2015; accepted for publication June 6, 2015; available ahead of print July 15, 2015.

Address for reprints: Yukihiro Tomita, MD, PhD, Department of Cardiovascular Surgery, National Hospital Organization Kyushu Medical Center, 1-8-1 Jigyo-hama, Chuo-ku, Fukuoka 812-8582, Japan (E-mail: ytomita@kyumed.jp). 0022-5223/\$36.00

Copyright (c) 2015 by The American Association for Thoracic Surgery http://dx.doi.org/10.1016/j.jtcvs.2015.06.022
}

the anterior mitral leaflet or both mitral leaflets. A broad spectrum of reconstructive techniques has been developed to treat complex MV pathology. ${ }^{1-4}$ Of these techniques, quadrangular resection of the prolapsing segment with or without sliding plasty has been the standard technique for the repair of PML. ${ }^{1}$ Limited triangular resection of PML has also been reported as a good alternative procedure that significantly reduces resection size and eliminates annular compression. ${ }^{2}$ In addition to these leaflet resection procedures, $\mathrm{MV}$ repair by chordal replacement with expanded polytetrafluoroethylene (ePTFE) sutures is a technique that shows high effectiveness and reliability in patients with PML prolapse. ${ }^{3,4}$ Furthermore, we previously reported this technique could also be applied to anterior or bilateral mitral 


$$
\begin{aligned}
& \text { Abbreviations and Acronyms } \\
& \begin{array}{ll}
\mathrm{BP} & =\text { blood pressure } \\
\mathrm{Ea} & =\text { effective arterial elastance } \\
\mathrm{Ea} / \mathrm{Ees} & =\text { ventriculoarterial coupling } \\
\mathrm{Ees} & =\text { end-systolic elastance } \\
\mathrm{EF} & =\text { ejection fraction } \\
\mathrm{e}-\mathrm{PTFE} & =\text { expanded polytetrafluoroethylene } \\
\mathrm{LV} & =\text { left ventricle } \\
\mathrm{LVMI} & =\text { left ventricle mass index } \\
\mathrm{MR} & =\text { mitral regurgitation } \\
\mathrm{MV} & =\text { mitral valve } \\
\mathrm{PML} & =\text { posterior mitral leaflet } \\
\text { SW/PVA } & =\text { stroke work to pressure-volume area } \\
\mathrm{TAP} & =\text { tricuspid annuloplasty }
\end{array}
\end{aligned}
$$

leaflet prolapse, as well as uncommon MV prolapse..$^{5-8}$ However, the effect of the respective reconstructive techniques on left ventricular (LV) function remains unclear.

Parameters such as LV cavity dimensions and ejection fraction (EF) have been widely used in a number of studies to detect subclinical LV myocardial dysfunction for chronic degenerative MR. However, LV dysfunction as assessed by echocardiography is often underestimated in patients with severe MR because of a systolic unloading effect resulting from low-resistance ejection to the left atrium. ${ }^{9,10}$ Therefore, EF might not be a precise index of LV systolic contractility in patients with MR.

End-systolic elastance (Ees), effective arterial elastance $(\mathrm{Ea})$, ventriculoarterial coupling $(\mathrm{Ea} / \mathrm{Ees})$, and the stroke work to pressure-volume area ratio (SW/PVA) enable analysis of LV contractility, afterload, and ventricular efficiency. ${ }^{11,12}$ Previously, LV performance was analyzed in patients undergoing MV surgery (asymptomatic patients vs symptomatic patients, or MV repair vs MV replacement). ${ }^{13,14}$ In our study, we hypothesized that the choice of operative technique (chordal replacement or leaflet resection) could influence postoperative LV function in patients undergoing MV repair for PML prolapse. Therefore, we sought to assess postoperative LV function, including LV mechanics, in patients undergoing MV repair with chordal replacement in comparison to patients with leaflet resection, and to investigate determinants of postoperative LV function in multivariate analysis.

\section{METHODS}

\section{Study Population}

This study was approved by the institutional review board of our institution, and the medical records of patients undergoing MV repair for chronic severe MR were reviewed retrospectively. The institutional review board waived the requirement for obtaining individual consent.
From April 2006 to September 2014, isolated MV repair for PML prolapse was performed in 72 patients with chronic severe MR. We included patients undergoing concomitant tricuspid annuloplasty (TAP) $(\mathrm{n}=24)$ or the maze procedure $(\mathrm{n}=14)$. One patient underwent MV repair with quadrangular resection for recurrence of PML prolapse 10 years after MV repair with chordal replacement. The MR was assessed by transesophageal or transthoracic echocardiography before and $\sim 1$ month after the surgery. It was graded according to the published guidelines using an integrated approach that included valvular morphologic characteristics, regurgitant jet size in the left atrium, proximal regurgitant jet width, and pulmonary venous flow pattern. ${ }^{15}$ No patients underwent $\mathrm{MV}$ replacement following unsuccessful repair.

\section{Surgical Procedure}

The MV repair was performed under cardiopulmonary bypass, with aortic and bicaval cannulation and tepid hypothermia. Myocardial protection was achieved using antegrade and retrograde cardioplegia. The MV was exposed through a superior transseptal approach $(n=29)$ or in left atriotomy through the interatrial groove $(n=43)$. The standard technique for MV repair was performed according to the anatomic lesions responsible for MR. MV repair for the PML prolapse was performed using artificial chordal replacement with e-PTFE $(\mathrm{n}=30)$, quadrangular resection $(\mathrm{n}=30)$, and triangular resection $(\mathrm{n}=12)$.

In the chordal replacement technique, briefly, the double-armed sutures (CV-4 e-PTFE sutures) are passed twice through the fibrous portion of the papillary muscle head that anchors the elongated or ruptured chordae. The 2 arms of the suture are then brought up to the free margin of the leaflet and passed through the point where the original chordae were attached (thickened portion of the leaflet). The needle is brought from the ventricular side of the leaflet to its atrial side and then passed once more through the leaflet. The length of the e-PTFE chordae is adjusted by referring to the contact area of the opposite leaflet. Once the length is adjusted, both ends of the suture are passed through the leaflet again and tied together on the ventricular side. We did not use any pledgets. When the prolapsed portion was wide, another e-PTFE suture was placed in the same manner. ${ }^{5-8}$

Meanwhile, the leaflet resection was performed using standard techniques of resection in the redundant posterior leaflet tissue. ${ }^{1,2}$ After the resection of PML prolapse, the approximation of the leaflet remnants was followed by using interrupted sutures. The MV repair was completed by a sliding annuloplasty or annular plication whenever necessary. No concomitant procedure to chordal replacement or leaflet resection was performed in any of the patients. Ring annuloplasty (Cosgrove ring, $\mathrm{n}=20$; Edwards Lifesciences, Irvine, Calif; Physio ring, $\mathrm{n}=52$; Edwards Lifesciences) was performed in all cases. The ring size for annuloplasty was chosen according to the area of the anterior leaflet. The choices of the annuloplasty ring and repair technique were determined according to surgeon preference.

Twenty-four patients with functional tricuspid regurgitation underwent ring TAP (Edwards Lifesciences) (9 patients) or suture TAP (Kay's procedure) (15 patients) with concomitant MV repair.

For evaluating residual MR, cold cardioplegic solution and saline solution were injected into the LV cavity. The repair was considered acceptable when the regurgitation was less than trivial during testing. After removal of the cardiopulmonary bypass, the presence of residual MR was reevaluated in all cases by intraoperative transesophageal echocardiography.

\section{Echocardiograph Data}

The MR severity and LV function were assessed by transthoracic or transesophageal echocardiography before and $\sim 1$ month after MV repair. LV volume was calculated by the Teichholz M-mode method using 
echocardiography data, LV end-diastolic dimension, and end-systolic dimension. ${ }^{16}$ Moreover, the EF (\%) was calculated as follows:

$\mathrm{EF}=(1-\mathrm{LV}$ end-systolic volume $/ \mathrm{LV}$ end-diastolic volume $) \times 100$

LV mechanics. Arterial blood pressure (BP) was measured by the Korotkoff technique using the manchette method. Systolic and diastolic pressure values corresponded to the onset of phase I and V Korotkoff sounds, respectively. Diastolic Korotkoff phase IV was used when the sounds were audible even after complete deflation of the manchette cuff. ${ }^{17}$ The mean arterial pressure was calculated as follows:

Mean arterial pressure $=($ systolic $\mathrm{BP}-$ diastolic $\mathrm{BP}) / 3+$ diastolic $\mathrm{BP}$

The calculation of Ees (contractility) and Ea (afterload) were performed by an approximation method as previously described. ${ }^{13,14,18}$ The approximation of Ees and Ea were as follows:

Ees $=$ mean arterial pressure $/$ minimal LV volume

$\mathrm{Ea}=$ maximal $\mathrm{LV}$ pressure $/($ maximal $\mathrm{LV}$ volume - minimal $\mathrm{LV}$ volume $)$

Maximal LV pressure and volume were defined as being the same as the systolic BP and LV end-diastolic volume, respectively. The minimal LV volume was defined as being the same as the LV end-systolic volume. The LV volume was normalized to body surface area. Ea/Ees ${ }^{12}$ and SW/ PVA were calculated as indexes of LV efficiency. The SW/PVA (\%) was calculated as follows ${ }^{19}$ :

$$
\mathrm{SW} / \mathrm{PVA}=1 /(1+0.5 \mathrm{Ea} / \text { Ees }) \times 100
$$

LV mass index (LVMI). The LV mass was calculated in grams as follows ${ }^{20}$ :

$$
\begin{aligned}
\mathrm{LV} \text { mass }= & 0.80 \times(1.04 \times[\mathrm{LV} \text { end-diastolic dimension } \\
& + \text { posterior wall thickness in diastole } \\
& + \text { septal wall thickness in diastole }]^{3} \\
& \left.-[\mathrm{LV} \text { end-diastolic dimension }]^{3}\right)+0.6
\end{aligned}
$$

The results obtained were indexed to the body surface area and expressed as grams per meters ${ }^{2}$.

Moreover, to distinguish the effect of LV function in MV surgery using chordal replacement from that using leaflet resection, the changes in postoperative parameters (LVEF, LVMI, Ees, Ea, Ea/Ees, and SW/PVA) were calculated as follows:

Relative change $(\%)=($ postoperative parameter - preoperative parameter $) /$ preoperative parameter $\times 100$

\footnotetext{
Statistical Analysis

Categorical variables were expressed as frequencies and percentages, and continuous variables as means \pm standard deviations. On the other hand, the changes in postoperative parameters (LVMI, LVEF, Ees, Ea, $\mathrm{Ea} / \mathrm{Ees}$, and SW/PVA) were expressed as means \pm standard error. The Mann-Whitney $U$ test (unpaired data) and Wilcoxon rank sum test (paired samples) were used to compare continuous variables, whereas Fisher exact test was used to compare categorical variables. The sample size of $72 \mathrm{pa}-$ tients undergoing MV repair (fixing $\alpha=0.05,1-\beta=0.8$, and effect size $=0.7)$ was sufficient for statistical comparisons of unpaired and paired samples.

We performed univariate regression analysis with LVMI, LVEF, Ees, Ea, $\mathrm{Ea} / \mathrm{Ees}$, and SW/PVA as independent variables. Then, multivariate analysis based on stepwise multiple linear regression was performed among
}

variables with significant univariate correlations. A $P$ value $<.05$ was considered statistically significant. The data were analyzed using the statistical analysis system software JMP 11.0.0 (SAS Institute Inc, Cary, NC).

\section{RESULTS \\ Patients' Characteristics and Surgical Data}

Table 1 shows the patients' characteristics and surgical data. Of the study population, there were 47 men and 25 women; the mean age was $62.9 \pm 12.9$ years (range, 3387 years). The preoperative electrocardiogram revealed atrial fibrillation in 16 patients. Fifty-nine patients were designated as New York Heart Association functional class I or II, and 13 were designated as class III or IV. In terms of preoperative characteristics, no differences were observed between the chordal replacement and leaflet resection groups. With respect to surgical data, the superior transseptal approach and TAP were performed more frequently in the chordal replacement group than in the leaflet resection group (each parameter $P<.001$ ). Meanwhile, the Cosgrove ring was used more frequently in MV repair with leaflet resection than in that with chordal replacement $(P<.001)$. The mean annuloplasty ring size was observed to be $28.4 \pm 1.4 \mathrm{~mm}$ for both groups $(P=.975)$. Although the aortic crossclamping time was comparable between both groups $(P=.096)$, the cardiopulmonary bypass time was significantly longer in the chordal replacement group than that in the leaflet resection group $(P=.011)$. No perioperative or hospital deaths were recorded.

\section{Hemodynamic Data}

The preoperative and postoperative hemodynamic data for MV repair with chordal replacement or leaflet resection are shown in Table 2. The LVMI significantly decreased early after surgery for both the chordal replacement and leaflet resection groups (each $P<.0001$ ). However, the preoperative and postoperative LVMI was comparable between groups ( $P=.533$ and $P=.694$, respectively). Meanwhile, the LVEF decreased early after surgery in both groups $(P=.060$ and $P<.0001$, respectively). The postoperative LVEF in the chordal replacement group was significantly higher than that in the leaflet resection group $(P=.033)$.

\section{Mechanics}

Table 3 shows the results for the LV mechanics before and after MV repair for PML prolapse. The preoperative and postoperative Ees was comparable between the chordal replacement and leaflet resection groups $(P=.401$ and $P=.101$, respectively). Although marginally significant, the Ees increased and decreased in the chordal replacement and leaflet resection groups after surgery, respectively (each $P=.079$ ). Meanwhile, the Ea increased significantly after surgery in both groups (each $P<.0001$ ). The preoperative and postoperative Ea was comparable between the chordal replacement and leaflet resection groups $(P=.914$ and 
TABLE 1. Patients' preoperative characteristics and surgical data

\begin{tabular}{|c|c|c|c|c|}
\hline Parameter & Total $(\mathbf{n}=72)$ & Chordal replacement $(\mathbf{n}=\mathbf{3 0})$ & Leaflet resection $(n=42)$ & $P$ value \\
\hline \multicolumn{5}{|l|}{ Preoperative data } \\
\hline Age, y & $62.9 \pm 12.9$ & $62.2 \pm 15.1$ & $63.5 \pm 11.3$ & .771 \\
\hline Male & $47(65)$ & $20(28)$ & $27(37)$ & .835 \\
\hline BSA, $\mathrm{m}^{2}$ & $1.63 \pm 0.20$ & $1.66 \pm 0.21$ & $1.61 \pm 0.19$ & .398 \\
\hline NYHA functional class III or IV & $13(18)$ & $8(11)$ & $5(7)$ & .111 \\
\hline Previous cardiac operation & $1(1.4)$ & $0(0)$ & $1(1.4)$ & .398 \\
\hline Af or AF & $16(22)$ & $9(12)$ & $7(10)$ & .183 \\
\hline Systolic PAP, mm Hg & $38.0 \pm 15.2$ & $41.2 \pm 16.3$ & $35.7 \pm 14.1$ & .119 \\
\hline Mean PAP, mm Hg & $24.0 \pm 10.2$ & $26.0 \pm 10.6$ & $22.5 \pm 9.7$ & .082 \\
\hline LVEDD, mm & $56.4 \pm 7.0$ & $57.8 \pm 6.6$ & $55.4 \pm 7.2$ & .375 \\
\hline LVESD, mm & $33.9 \pm 6.8$ & $35.5 \pm 6.4$ & $32.7 \pm 7.0$ & .173 \\
\hline$\%$ LVEF & $64.4 \pm 9.5$ & $62.9 \pm 8.9$ & $65.5 \pm 9.9$ & .401 \\
\hline \multicolumn{5}{|l|}{ Surgical data } \\
\hline $\begin{array}{l}\text { Approach (superior transseptal approach/left atrium } \\
\text { approach from the right side) }\end{array}$ & $29 / 43(40 / 60)$ & $23 / 7(32 / 10)$ & $6 / 36(8 / 50)$ & $<.001$ \\
\hline \multicolumn{5}{|l|}{ Concomitant procedure } \\
\hline TAP, n $(\%)$ & $24(33)$ & $18(25)$ & $6(8)$ & $<.001$ \\
\hline Maze, n (\%) & $14(20)$ & $7(10)$ & $7(10)$ & .328 \\
\hline Type of artificial ring* & 20/52 (28/72) & $2 / 28(3 / 39)$ & $18 / 24(25 / 33)$ & $<.001$ \\
\hline Mean size of artificial ring, $\mathrm{mm}$ & $28.4 \pm 1.4$ & $28.4 \pm 1.4$ & $28.4 \pm 1.4$ & .975 \\
\hline Cardiopulmonary bypass time, min & $171 \pm 35$ & $182 \pm 31$ & $164 \pm 37$ & .011 \\
\hline Aortic crossclamping time, min & $122 \pm 31$ & $128 \pm 26$ & $117 \pm 33$ & .096 \\
\hline
\end{tabular}

Values are presented as mean \pm standard deviation or number (percentage). $B S A$, Body surface area; $N Y H A$, New York Heart Association; $A f$, atrial fibrillation; $A F$, atrial flutter; $P A P$, pulmonary artery pressure; $L V E D D$, left ventricular end-diastolic dimension; $L V E S D$, left ventricular end-systolic dimension; $L V E F$, left ventricular ejection fraction; TAP, tricuspid annuloplasty. *Cosgrove (Edwards Lifesciences, Irvine, Calif) or Physio (Edwards Lifesciences) ring.

$P=.169$, respectively). As parameters of LV efficiency, both $\mathrm{Ea} /$ Ees and SW/PVA were significantly deteriorated after surgery in both groups (each $P<.0001$ ). Interestingly, both parameters were comparable preoperatively in the groups (each $P=.519$ ), but were significantly better after surgery in the chordal replacement group than in the leaflet resection group (each $P=.028$ ) (Figure 1).

\section{Relative Change in LVMI, LVEF, Ees, Ea, Ea/Ees, and SW/PVA}

Tables 2 and 3 show the comparison of changes in postoperative parameters in the chordal replacement group with those in the leaflet resection group. The change of Ees in the chordal replacement group increased significantly more than that in the leaflet resection group $(19.0 \% \pm 6.5 \%$ vs $-1.3 \% \pm 7.7 \% ; P=.012)$.
Meanwhile, chordal replacement resulted in significantly smaller reductions in LVEF and SW/PVA than leaflet resection $(-4.8 \% \pm 3.2 \%$ vs $-16.7 \% \pm 2.5 \% ; P=.005$ and $-4.3 \% \pm 2.5 \%$ vs $-13.4 \% \pm 2.0 \% ; P=.008)$ and significantly smaller increases in $\mathrm{Ea} / \mathrm{Ees}(32.0 \% \pm 11.4 \%$ vs $89.3 \% \pm 16.1 \% ; P=.007)$.

\section{Determinants of LVMI, LVEF, Ees, Ea, Ea/Ees, and SW/PVA}

Table 4 shows determinants of LVMI, LVEF, and LV mechanics in all patients undergoing MV repair. Operative technique (chordal replacement or leaflet resection) demonstrated strong correlations with LVEF, Ea/Ees, and SW/PVA in univariate analysis. In multivariate analysis, operative technique was a significant determinant of LVEF and SW/PVA. Meanwhile, TAP was a significant determinant of Ea/Ees only.

TABLE 2. Left ventricular mass index (LVMI) and left ventricular ejection fraction (LVEF) before and after surgery

\begin{tabular}{|c|c|c|c|c|c|}
\hline & Preoperative & Postoperative & $P$ value* & Relative change, $(\%)$ & $P$ value \\
\hline \multicolumn{6}{|l|}{ LVMI, $\mathrm{g} / \mathrm{m}^{2}$} \\
\hline Chordal replacement $(\mathrm{n}=30)$ & $150.0 \pm 42.9$ & $111.1 \pm 32.6$ & $<.0001$ & $-24.2 \pm 3.1$ & .689 \\
\hline Leaflet resection $(n=42)$ & $140.5 \pm 29.6$ & $108.5 \pm 24.6$ & $<.0001$ & $-20.1 \pm 3.3$ & \\
\hline$P$ value $\dagger$ & .533 & .694 & & & \\
\hline \multicolumn{6}{|l|}{ LVEF, \% } \\
\hline Chordal replacement $(\mathrm{n}=30)$ & $62.9 \pm 8.9$ & $59.0 \pm 9.2$ & .060 & $-4.8 \pm 3.2$ & .005 \\
\hline Leaflet resection $(n=42)$ & $65.5 \pm 9.9$ & $53.9 \pm 9.5$ & $<.0001$ & $-16.7 \pm 2.5$ & \\
\hline$P$ value $\dagger$ & 0.404 & 0.033 & & & \\
\hline
\end{tabular}

Preoperative and postoperative data are presented as mean \pm standard deviation. Relative changes are presented as mean \pm standard error. $L V M I$, Left ventricular mass index; $L V E F$, left ventricular ejection fraction. *Preoperative versus postoperative. †Chordal replacement versus leaflet resection. 
TABLE 3. Left ventricle mechanics before and after surgery

\begin{tabular}{|c|c|c|c|c|c|}
\hline & Preoperative & Postoperative & $P$ value* & Relative change, $\%$ & $P$ value \\
\hline \multicolumn{6}{|l|}{ Ees, $\mathrm{mm} \mathrm{Hg} \times \mathrm{m}^{2} / \mathrm{mL}$} \\
\hline Chordal replacement $(\mathrm{n}=30)$ & $2.1 \pm 0.8$ & $2.3 \pm 0.8$ & .079 & $19.0 \pm 6.5$ & .012 \\
\hline Leaflet resection $(n=42)$ & $2.4 \pm 1.4$ & $2.0 \pm 0.6$ & .079 & $-1.3 \pm 7.7$ & \\
\hline$P$ value $\dagger$ & .401 & .101 & & & \\
\hline \multicolumn{6}{|l|}{$\mathrm{Ea}, \mathrm{mm} \mathrm{Hg} \times \mathrm{m}^{2} / \mathrm{mL}$} \\
\hline Chordal replacement $(\mathrm{n}=30)$ & $1.6 \pm 0.4$ & $2.1 \pm 0.7$ & $<.0001$ & $44.4 \pm 10.2$ & .181 \\
\hline Leaflet resection $(n=42)$ & $1.6 \pm 0.5$ & $2.3 \pm 0.6$ & $<.0001$ & $56.0 \pm 8.3$ & \\
\hline$P$ value $\dagger$ & .914 & .169 & & & \\
\hline \multicolumn{6}{|l|}{$\mathrm{Ea} / \mathrm{Ees}$} \\
\hline Chordal replacement $(\mathrm{n}=30)$ & $0.8 \pm 0.3$ & $1.0 \pm 0.4$ & $<.0001$ & $32.0 \pm 11.4$ & .007 \\
\hline Leaflet resection $(n=42)$ & $0.8 \pm 0.3$ & $1.3 \pm 0.6$ & $<.0001$ & $89.3 \pm 16.1$ & \\
\hline$P$ value $\dagger$ & .519 & .028 & & & \\
\hline \multicolumn{6}{|l|}{ SW/PVA $(\%)$} \\
\hline Chordal replacement $(\mathrm{n}=30)$ & $71.1 \pm 7.6$ & $67.4 \pm 7.6$ & $<.0001$ & $-4.3 \pm 2.5$ & .008 \\
\hline Leaflet resection $(n=42)$ & $72.9 \pm 8.5$ & $62.7 \pm 8.5$ & $<.0001$ & $-13.4 \pm 2.0$ & \\
\hline$P$ value $\dagger$ & .519 & .028 & & & \\
\hline
\end{tabular}

Preoperative and postoperative data are presented as mean \pm standard deviation. Relative changes are presented as mean \pm standard error. Ees, End-systolic elastance; Ea, effective arterial elastance; Ea/Ees, ventriculoarterial coupling; SW/PVA, stroke work/pressure-volume area ratio. *Preoperative versus postoperative. †Chordal replacement versus leaflet resection.

\section{DISCUSSION}

The major findings in this study were that the change in LV contractility (Ees) was marginally significantly different for both groups, with the nature of the change (increase vs decrease) differing between them; LV afterload (Ea) increased significantly for both groups, with the extent of the increase comparable between them; LV efficiency (Ea/ Ees and SW/PVA) deteriorated; postoperative LV efficiency in patients undergoing MV repair with chordal replacement was superior to that with leaflet resection; and operative technique (chordal replacement or leaflet resection) was a determinant of postoperative LVEF and SW/PVA in multivariate analysis.

MV repair using the leaflet resection technique is the most widely adopted technique for correcting MR resulting from PML prolapse, and has shown excellent short-term and long-term results. ${ }^{21,22}$ However, these techniques result in immobilization of the PML and some degree of impairment in its physiologic role. ${ }^{23}$ Moreover, annular plication or sliding annuloplasty following leaflet resection may further increase leaflet restriction and surgical complexity. Meanwhile, the effectiveness and reliability of MV repair with chordal replacement have been demonstrated in not only anterior mitral leaflet prolapse, but also PML prolapse. .-8,24 $^{-1}$ The MV repair with chordal replacement is associated with reduced leaflet morbidity, larger surface of coaptation, and preserved ventriculoannular continuity. ${ }^{25}$ Although both the chordal replacement and leaflet resection techniques for MV repair have been shown to have comparable excellent short-term and long-term results, the differences in valve and LV performance between the approaches have remained unclear. Our findings provide evidence that patients undergoing chordal replacement for MV repair have superior postoperative LV performance than those
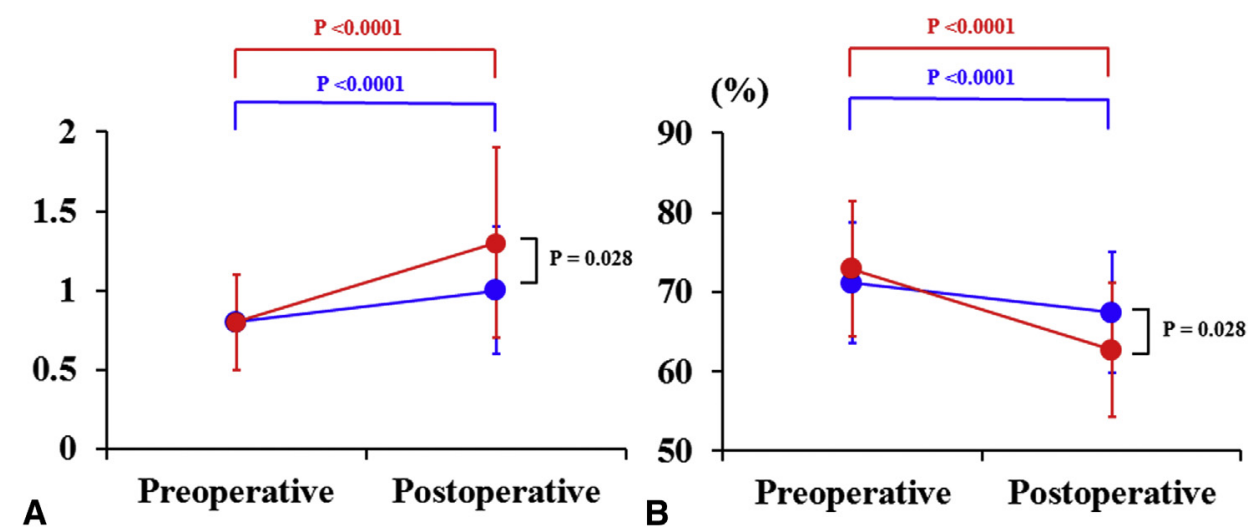

FIGURE 1. Changes in left ventricle efficiency in A, ventriculoarterial coupling and B, stroke work/pressure-volume area ratio in patients undergoing mitral valve repair using chordal replacement (blue circle) or using leaflet resection (red circle). 
TABLE 4. Preoperative and intraoperative determinants of left ventricular mass index (LVMI), left ventricular ejection fraction (LVEF), and left ventricle mechanics

\begin{tabular}{|c|c|c|c|c|}
\hline & \multicolumn{2}{|c|}{ Univariate } & \multicolumn{2}{|c|}{ Multivariate } \\
\hline & $r$ & $\boldsymbol{P}$ & $\beta$ & $\boldsymbol{P}$ \\
\hline \multicolumn{5}{|l|}{ LVMI } \\
\hline Operative technique* & 0.104 & .386 & & \\
\hline $\mathrm{Af}_{\dagger}^{\dagger}$ & -0.069 & .565 & & \\
\hline $\mathrm{TAP}_{\dagger}^{\dagger}$ & -0.090 & .451 & & \\
\hline Cardiopulmonary bypass time & -0.051 & .671 & & \\
\hline \multicolumn{5}{|l|}{ LVEF } \\
\hline Operative technique* & -0.334 & .004 & -0.244 & $.030 \S$ \\
\hline $\mathrm{Af}^{\dagger}$ & 0.318 & .006 & & \\
\hline $\mathrm{TAP}_{\ddagger}^{\dagger}$ & 0.370 & .001 & & \\
\hline Cardiopulmonary bypass time & 0.422 & $<.001$ & 0.360 & $.002 \S$ \\
\hline \multicolumn{5}{|l|}{ Ees } \\
\hline Operative technique* & -0.222 & .061 & & \\
\hline $\mathrm{Af} \dagger$ & 0.168 & .159 & & \\
\hline $\mathrm{TAP}_{\dagger}^{\dagger}$ & 0.237 & .046 & & \\
\hline Cardiopulmonary bypass time & 0.299 & .011 & 0.299 & .0119 \\
\hline \multicolumn{5}{|l|}{ Ea } \\
\hline Operative technique* & 0.106 & .378 & & \\
\hline $\mathrm{Af} \dagger$ & -0.214 & .072 & & \\
\hline $\mathrm{TAP}_{\ddagger}^{\dagger}$ & -0.149 & .212 & & \\
\hline Cardiopulmonary bypass time & -0.193 & .104 & & \\
\hline \multicolumn{5}{|l|}{$\mathrm{Ea} / \mathrm{Ees}$} \\
\hline Operative technique* & 0.304 & .009 & & \\
\hline $\mathrm{Af}^{\dagger}$ & -0.274 & .020 & & \\
\hline $\mathrm{TAP}_{\ddagger}^{\dagger}$ & -0.311 & .008 & -0.328 & $.008 \|$ \\
\hline Cardiopulmonary bypass time & -0.282 & .016 & & \\
\hline \multicolumn{5}{|l|}{ SW/PVA } \\
\hline Operative technique* & -0.327 & .005 & -0.249 & $.030 \#$ \\
\hline $\mathrm{Af}_{\dagger}^{\dagger}$ & 0.311 & .008 & & \\
\hline $\mathrm{TAP}_{\ddagger}^{\dagger}$ & 0.358 & .002 & & \\
\hline Cardiopulmonary bypass time & 0.373 & .001 & 0.309 & $.007 \#$ \\
\hline
\end{tabular}

$A f$, Atrial fibrillation; TAP, tricuspid annuloplasty; Ees, end-systolic elastance; $E a$, effective arterial elastance; Ea/Ees, ventriculoarterial coupling; SW/PVA, stroke work/pressure-volume area ratio; $L V M I$, left ventricular mass index; $L V E F$, left ventricular ejection fraction. $*$ Chordal replacement $=1$, leaflet resection $=2$. $\dagger$ With $\mathrm{Af}=1$, without $\mathrm{Af}=0$. $\ddagger$ With $\mathrm{TAP}=1$, without $\mathrm{TAP}=0 . \S R^{2}$ and adjusted $R^{2}$ of the model selected for multivariate analysis, 0.233 and 0.211 , respectively. $\llbracket R^{2}$ and adjusted $R^{2}$ of the model selected for multivariate analysis, 0.090 and 0.077 , respectively. $\| R^{2}$ and adjusted $R^{2}$ of the model selected for multivariate analysis, 0.097 and 0.084 , respectively. $\# R^{2}$ and adjusted $R^{2}$ of the model selected for multivariate analysis, 0.196 and 0.173 , respectively.

undergoing leaflet resection in the early postoperative course.

The decrease in EF early after MV surgery has been shown to compensate for alterations in LV volume and dimension rather than result from postoperative LV dysfunction due to impaired myocardial contractility. ${ }^{26}$ Moreover, the LV response to MV surgery for chronic MR has been postulated to depend largely on the functional state of the ventricle before surgery and the surgical procedure that is performed. ${ }^{27}$ The authors of that previous study $^{27}$ concluded that systolic function after MV surgery for chronic MR is preserved by maintaining continuity between the mitral apparatus and the LV wall. In our results, the patients undergoing MV repair with leaflet resection had a more deteriorated LVEF than those with chordal replacement. Moreover, although the differences were marginally significant, the Ees in the chordal replacement and leaflet resection groups increased and decreased after surgery, respectively $(P=.079)$. These findings suggest that chordal replacement can prevent systolic functional impairment by preserving ventriculoannular continuity and/or preventing leaflet morbidity.

Starling ${ }^{28}$ determined that LV efficiency for performing forward SW improved 1 year after MV surgery by measuring LV function with radionuclide and micromanometer-derived pressure-volume loops acquired over a range of loading conditions. This finding is not in accordance with our results. The reason underlying this discrepancy is that the SW values are crucially different between the 2 studies. In MR, the total SW must be divided into the forward SW and the ineffective work of the volume regurgitation into the low-impedance left atrium. However, in our study, because of the impossibility of evaluating the forward SW, the LV efficiency for performing total SW was evaluated before and after surgery. Moreover, Starling showed that despite impaired LV efficiency for performing forward SW in patients with long-term MR, LV efficiency for performing total SW was not impaired. ${ }^{29}$ This finding suggests that LV efficiency for performing total SW underestimates the impaired LV function in patients with MR. Therefore, in our study, the comparison of LV efficiency before and after surgery should be interpreted with care. However, it is noteworthy that despite the comparable preoperative LV efficiency, the postoperative LV efficiency in the chordal replacement group was superior to that in the leaflet resection group. Future research is needed to clarify whether chordal replacement and leaflet resection is superior for MV repair.

By contrast, in multivariate analysis, the determinants of postoperative LV efficiency (ie, Ea/Ees and SW/PVA) were unexpectedly different factors. This discrepancy may be partly explained by the fact that operative technique (chordal replacement or leaflet resection) was highly correlated with TAP in simple linear regression analysis $(r=-0.478)$. To further clarify this point, a randomized control trial or propensity score matched analysis in a large sample is needed to more precisely assess the influence of operative technique on MV repair.

The type of annuloplasty ring should also be taken into consideration in evaluating LV performance after surgery. The Physio ring was designed to add a degree of flexibility to the classic rigid ring while conforming to the configuration of the normal MV annulus during systole. ${ }^{30}$ After performing a propensity score analysis, Manabe and colleagues $^{31}$ found that the postoperative cardiac function in patients who underwent mitral ring annuloplasty with a 
semirigid prosthetic ring was similar to that with a flexible ring or band. However, the differences between the semirigid and flexible rings on postoperative cardiac function have not been fully clarified. In our study, a higher percentage of patients who underwent leaflet resection received the Cosgrove ring compared with those who underwent chordal replacement. The effect of this difference on LV performance after surgery is unclear but warrants further investigation.

In LVMI, it remains unclear whether significant LV mass regression proceeds concurrently with the recovery of normal LV geometry after MV repair. Shafii and colleagues $^{32}$ showed that LV mass regression, which occurred within the first postoperative year and persisted to 5 years, was incomplete after MV surgery. Reverse LV remodeling early after MV repair is highly compatible with the results of our study. Meanwhile, Stulak and colleagues ${ }^{33}$ indicated a greater residual LVMI in patients with a reduced preoperative LVEF and secondary tricuspid regurgitation, also suggesting incomplete reverse remodeling and advantages to early surgery. In this study, the LV mass regression early after MV repair using chordal replacement was similar to that using leaflet resection. However, no follow-up study of LV mass regression has compared the surgical techniques. Further study is needed to verify the superiority of reverse LV remodeling between chordal replacement and leaflet resection.

Our study had several limitations. First, the data were obtained retrospectively using charts and a database review. Second, the Simpson method is more suitable than the Teichholz method for calculating the LV volume; however, only the LV diameter values were available in our study. Third, the inaccuracy of LV volume calculated in patients with atrial fibrillation was another inherent limitation. Assessment of LV function in atrial fibrillation is difficult because of beat-to-beat variation. ${ }^{34}$ Therefore, it is necessary to average many beats to obtain an accurate evaluation during atrial fibrillation. ${ }^{35}$ We had no choice but to calculate LV volume based on previous echocardiographic data. Fourth, the approximation of Ees and Ea in this study had inherent limitations and is not as accurate as the measurements obtained using a conductance catheter system. Moreover, the volume intercept could not be measured. The validation has been performed only on normal canine hearts, which are different from diseased human hearts, notably with regard to MR. However, because these approximations were validated using the canine right heart bypass model, which can draw the maximum capacity, ${ }^{18}$ we believe the limitations of this approximation do not detract from the validity of our conclusions. Finally, the follow-up period was only 1 month after surgery. Hence, further studies evaluating midterm or long-term LV function after MV repair are required.

\section{CONCLUSIONS}

Our findings suggest that patients undergoing chordal replacement for MV repair have superior postoperative LV performance than those undergoing leaflet resection. Further studies are needed to clarify the differences in postoperative LV function between chordal replacement and leaflet resection. Longer-term follow-up will be required to determine whether this superior outcome is long-term.

\section{Conflict of Interest Statement}

Authors have nothing to disclose with regard to commercial support.

\section{References}

1. Carpentier A. Cardiac valve surgery-the "French correction" J Thorac Cardiovasc Surg. 1983;86:323-37.

2. Gazoni LM, Fedoruk LM, Kern JA, Dent JM, Reece TB, Tribble CG, et al. A simplified approach to degenerative disease: triangular resections of the mitral valve. Ann Thorac Surg. 2007;83:1658-64.

3. David TE. Replacement of chordae tendineae with expanded polytetrafluoroethylene sutures. J Card Surg. 1989;4:286-90.

4. Salvador L, Mirone S, Bianchini R, Regesta T, Patelli F, Minniti G, et al. A 20year experience with mitral valve repair with artificial chordae in 608 patients. $J$ Thorac Cardiovasc Surg. 2008;135:1280-7.

5. Tomita Y, Yasui H, Iwai T, Nishida T, Tatewaki H, Morita S, et al. Surgical application for a prolapse of the anterior mitral leaflet by replacing artificial chordae with polytetrafluoroethylene grafts. Surg Today. 2005;35:812-8.

6. Tomita Y, Yasui H, Iwai T, Nishida T, Morita S, Masuda M, et al. Extensive use of polytetrafluoroethylene artificial grafts for prolapse of posterior mitral leaflet. Ann Thorac Surg. 2004; 78:815-9.

7. Tomita Y, Yasui H, Tominaga R, Morita S, Masuda M, Kurisu K, et al. Extensive use of polytetrafluoroethylene artificial grafts for prolapse of bilateral mitral leaflets. Eur J Cardiothorac Surg. 2002;21:27-31.

8. Tomita Y, Yasui H, Tominaga R. Mitral valve repair for isolated double-orifice mitral valve with torn chordae. Ann Thorac Surg. 1997;64:1831-4.

9. Suri RM, Schaff HV, Dearani JA, Sundt TM, Daly RC, Mullany CJ, et al. Recovery of left ventricular function after surgical correction of mitral regurgitation caused by leaflet prolapse. J Thorac Cardiovasc Surg. 2009;137:1071-6.

10. Quintana E, Suri RM, Thalji NM, Daly RC, Dearani JA, Burkhart HM, et al. Left ventricular dysfunction after mitral valve repair-the fallacy of "normal" preoperative myocardial function. J Thorac Cardiovasc Surg. 2014;148:2752-62.

11. Suga H. Ventricular energetics. Physiol Rev. 1990;70:247-77.

12. Burkhoff D, Sagawa K. Ventricular efficiency predicted by an analytical model. Am J Physiol. 1986;250:R1021-7.

13. Imasaka K, Tomita Y, Tanoue Y, Tominaga R, Tayama E, Onitsuka H, et al. Early mitral valve surgery for chronic severe mitral regurgitation optimizes left ventricular performance and left ventricular mass regression. J Thorac Cardiovasc Surg. 2013;146:61-6.

14. Imasaka K, Motomatsu Y, Hori H, Kono T, Tanoue Y, Tayama E, et al. Ventricular energetics early after surgery for chronic mitral regurgitation: repair versus replacement. J Heart Valve Dis. 2013;22:804-9.

15. Zoghbi WA, Enriquez-Sarano M, Foster E, Grayburn PA, Kraft CD, Levine RA, et al. Recommendations for evaluation of the severity of native valvular regurgitation with two-dimensional and Doppler echocardiography. J Am Soc Echocardiogr. 2003;16:777-802.

16. Teichholtz LE, Kreulen T, Herman MV, Gorlin R. Problems in echocardiographic volume determinations: echocardiographic-angiographic correlations in the presence of absence of asynergy. Am J Cardiol. 1976;37:7-11.

17. Pickering TG, Hall JE, Apple LJ, Falkner BE, Graves J, Hill MN, et al. Recommendations for blood pressure measurement in humans and experimental animals: Part 1: blood pressure measurement in humans: a statement for professionals from the Subcommittee of Professional and Public Education of the American Heart Association Council on High Blood Pressure Research. Circulation. 2005;111:697-716.

18. Tanoue Y, Sese A, Ueno Y, Joh K, Hijii T. Bidirectional Glenn procedure improves the mechanical efficiency of a total cavopulmonary connection in highrisk Fontan candidates. Circulation. 2001;103:2176-80. 
19. Nozawa T, Yasumura Y, Futaki S, Tanaka N, Uenishi M, Suga H. Efficiency of energy transfer from pressure-volume area to external mechanical work increases with contractile state and decreases with afterload in the left ventricle of the anesthetized closed-chest dog. Circulation. 1988;77:1116-24.

20. Lang RM, Bierig M, Devereux RB, Flachskampf FA, Foster E, Pellikka PA, et al. Recommendations for chamber quantification: a report from the American Society of Echocardiography's Guidelines and Standards Committee and the Chamber Quantification Writing Group, developed in conjunction with the European Association of Echocardiography, a branch of the European Society of Cardiology. J Am Soc Echocardiogr. 2005;18: 1440-63.

21. Johnston DR, Gillinov AM, Blackstone EH, Griffin B, Stewart W, Sabik JF 3rd, et al. Surgical repair of posterior mitral valve prolapse: implications for guidelines and percuataneous repair. J Thorac Cardiovasc Surg. 2010;89:1385-94.

22. Braunberger E, Deloche A, Berrebi A, Abdallah F, Celestin JA, Meimoun P, et al. Very long-term results (more than 20 years) of valve repair with Carpentier's techniques in nonrheumatic mitral valve insufficiency. Circulation. 2001; 104(12 Suppl 1):I8-11.

23. Dreyfus GD, Corbi P, Rubin S, Aubert S. Posterior leaflet preservation in mitral valve prolapse: a new approach to mitral repair. J Heart Valve Dis. 2006;15: 528-30.

24. David TE, Armstrong S, Ivanov J. Chordal replacement with polytetrafluoroethylene sutures for mitral valve repair: a 25-year experience. J Thorac Cardiovasc Surg. 2013;145:1563-9.

25. Padala M, Powell SN, Croft LR, Thourani VH, Yoganathan AP, Adams DH. Mitral valve hemodynamics after repair of acute posterior leaflet prolapse: quadrangular resection versus triangular resection versus neochordoplasty. $J$ Thorac Cardiovasc Surg. 2009;138:309-15.

26. Suri RM, Schaff HV, Dearani JA, Sundt TM III, Daly RC, Mullany CJ, et al. Determinants of early decline in ejection fraction after surgical correction of mitral regurgitation. J Thorac Cardiovasc Surg. 2008;136:442-7.
27. Goldfine H, Aurigemma GP, Zile MR, Gaasch WH. Left ventricular length-forceshortening relations before and after surgical correction of chronic mitral regurgitation. J Am Coll Cardiol. 1998;31:180-5.

28. Starling MR. Effects of valve surgery on left ventricular contractile func tion in patients with long-term mitral regurgitation. Circulation. 1995;92: 811-8.

29. Starling MR. Left ventricular pump efficiency in long-term mitral regurgitation assessed by means of left ventricular-arterial coupling relations. Am Heart J. 1994;127:1324-35

30. Carpentier AF, Lessana A, Relland JY, Belli E, Mihaileanu S, Berrebi AJ, et al The "physio-ring": an advanced concept in mitral valve annuloplasty. Ann Thorac Surg. 1995;60:1177-86.

31. Manabe S, Kasegawa H, Fukui T, Tabata M, Shinozaki T, Shimokawa T, et al. Do semi-rigid prosthetic rings affect left ventricular function after mitral valve repair? Circ J. 2013;77:2038-42.

32. Shafii AE, Gillinov AM, Mihaljevic T, Stewart W, Batizy LH, Blackstone EH Changes in left ventricular morphology and function after mitral valve surgery. Am J Cardiol. 2012;110:403-8.

33. Stulak JM, Suri RM, Derani DJ, Burkhart HM, Sundt TM III, EnriquezSarano M, et al. Does early surgical intervention improve left ventricular mass regression after mitral valve repair for leaflet prolapse? J Thorac Cardiovasc Surg. 2011;141:122-9.

34. Kerr AJ, Williams MJ, Stewart RA. Ventricular rate and beat-to-beat variation of stroke volume in atrial fibrillation. Am J Cardiol. 2001;87:1116-9.

35. Dubreay SW, Falk RH. Optimal number of beats for the Doppler measurement of cardiac output in atrial fibrillation. J Am Soc Echocardiogr. 1997; 10:67-71.

Key Words: left ventricular performance, mitral valve repair, chordal replacement, leaflet resection

Readers who found these articles interesting may also like to read the following papers found in recent and future issues of our sister publications, Seminars in Thoracic and Cardiovascular Surgery and Operative Techniques in Thoracic and Cardiovascular Surgery!

\section{Acquired Cardiovascular Disease: Valvular Heart Disease}

Current Readings: Aortic Valve Sparing Operations. Tirone David. Semin Thorac Cardiovasc Surg 2014; Autumn; 26(3):231-238. News and Views: The CoreValve US Pivotal Trial. Michael Reardon. Semin Thorac Cardiovasc Surg 2014; Autumn; 26(3):179-186. State of the Art: Strategies and Devices to Minimize Stroke in Adult Cardiac Surgery. Richard M. Engelman. Semin Thorac Cardiovasc Surg 2015; Spring; 27(1):24-29.

State of the Art: Minimally Invasive Valve Surgery: When Less is More. Joseph Lamelas. Semin Thorac Cardiovasc Surg 2015; Spring; 27(1):49-56.

Discussion in Cardiothoracic Treatment and Care: Surgical Ablation for Atrial Fibrillation. Marc Gillinov. Semin Thorac Cardiovasc Surg 2015; Spring; 27(1): 65-79.

Original Submission: Hemodynamic performance of the aortic valve late after David I: An echocardiographic study. Antonino Rubino. Expected Publication October 2015.

Editorial Commentary: Back to David I. Tirone David. Expected Publication October 2015. Discussion in Cardiothoracic Treatment and Care: Aortic Valve/Root Repair. Tirone David. Expected Publication: December 2015.

Reoperative Aortic Valve Replacement After Previous Coronary Artery Bypass Grafting or Aortic Valve Replacement. Marc R. Moon. Oper Tech Thorac Cardiovasc Surg 2014; Winter; 19(4):482-499. 